Chapter 3: Learning and Memory in the Aging Brain:

The Function of Declarative and Nondeclarative Memory Over the Life Span

Nichole R. Lighthall, Ph.D.

Department of Psychology

University of Central Florida

Lindsay B. Conner, M.S.

Department of Psychology

University of Central Florida

Kelly S. Giovanello, Ph.D.

Department of Psychology and Neuroscience

and Biomedical Research Imaging Center,

The University of North Carolina at Chapel Hill 


\section{Learning and memory systems}

Human memory is not a unitary faculty. Rather, it consists of distinct learning and memory systems, each contributing in unique ways to the acquisition, retention, and subsequent retrieval of information. The current chapter focuses on age-related changes to long-term learning and memory systems defined as the acquisition and retention of information over long intervals of time (i.e., beyond working memory capacity). Long-term memory is often subdivided into declarative memory (the acquisition and retention of knowledge) and nondeclarative memory (experience-induced changes in performance). In this chapter, we draw on both behavioral and neuroimaging studies of young adults and older adults to describe the functional-anatomic architecture of multiple memory systems including declarative and nondeclarative memory. First, we present the neural correlates of the declarative memory system, followed by a discussion of how age-related changes to declarative memory mechanisms affect episodic memory while leaving semantic memory relatively intact. Then, we present the neural correlates of the nondeclarative memory system, followed by a discussion of how age-related changes to mechanisms of priming, classical conditioning, procedural, and reinforcement learning affect associated learning and memory performance with age. Finally, we discuss interactions across and between memory systems with age, and potential future directions in research on learning and memory function in the aging brain.

\section{Neural correlates of the declarative system}

Declarative memory encompasses the acquisition, long-term retention, and retrieval of events, facts, and concepts (Squire, 2009). Such knowledge can be retrieved at will and used in a variety of contexts. Declarative memory is typically subdivided based on whether memories are concerned with personally relevant events (i.e., episodic memory) or impersonal information (i.e., semantic memory). Broadly speaking, declarative learning and memory processes depend predominantly on the prefrontal cortex (PFC), medial temporal lobes (MTL), and lateral temporal cortex (see Figure 1). Research suggests that the PFC plays a supervisory role over other brain regions, including the MTL (Norman \& Shallice, 1986; Miller \& Cohen, 2001), via consciously controlled bias mechanisms (Buckner, 2003). During encoding, the PFC implements the processes that organize input to the MTL and during retrieval, the PFC mediates search and post-retrieval monitoring processes (Cabeza, 2006; Moscovitch, 1992). In contrast, the MTL, 
particularly the hippocampus, serves to bind the conceptual, perceptual, and affective components of an episodic event into an integrated memory trace (Eichenbaum, Yonelinas, \& Ranganath, 2007; Moscovitch, 1992). These binding processes operate both during the initial registration of novel events and when subjects retrieve recently acquired information (Gabrieli, Brewer, Desmond, \& Glover, 1997; Nyberg, McIntosh, Houle, Nilsson, \& Tulving, 1996), particularly during the encoding of experiences that are later remembered versus later forgotten. (Brewer, Zhao, Desmond, Glover, \& Gabrieli, 1998; Wagner et al., 1998). Finally, neuroimaging studies investigating the brain basis of semantic memory have observed neural activity in the inferior frontal gyri, left superior temporal gyrus, and bilateral supramarginal gyri - specifically during the production of semantic exemplars and judgments of semantic similarity (Dapretto \& Bookheimer, 1999; Poldrack et al., 1999; Friederici, Meyer, \& von Cramon, 2000; Wierenga et al., 2008; Tyler et al., 2010; Tyler et al., 2011; Zhuang, Johnson, Madden, Burke, \& Diaz, 2016).

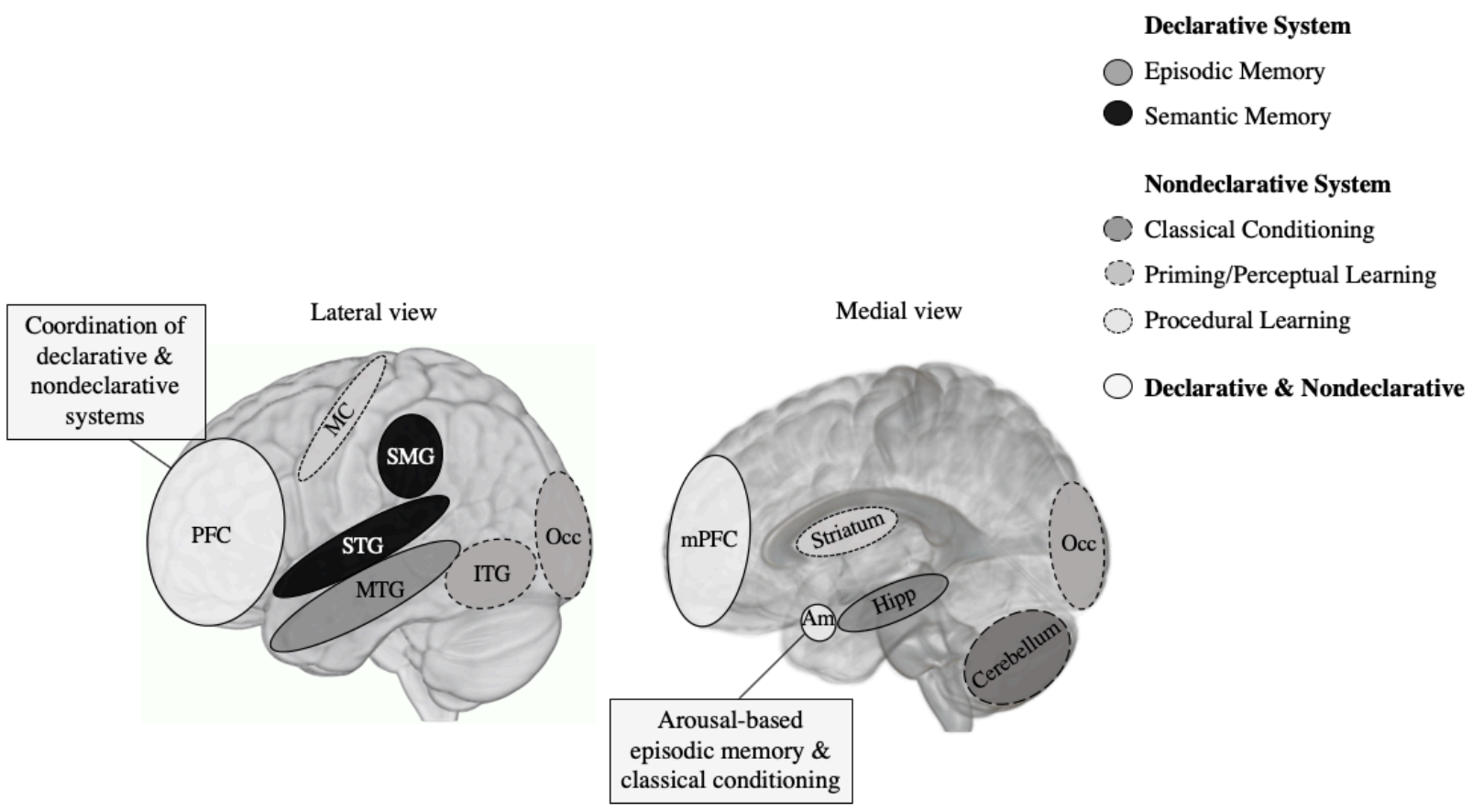

Figure 1. Primary brain structures associated with declarative and nondeclarative memory and learning. Generally, the declarative system (cool colors) relies on the prefrontal cortex (PFC) and temporal lobe, including the superior temporal (STG) and supramarginal (SMG) gyri for semantic memory and the middle temporal gyrus (MTG) - including the amygdala (Am) and hippocampus (hipp) - for episodic memory. The nondeclarative system (warm colors) includes the striatum and 
motor cortex (MC) for procedural learning, stimulus-relevant neocortical areas for priming and perceptual learning (occipital (Occ) \& inferior temporal gyrus (ITG)), and the amygdala and cerebellum for classical conditioning. Importantly, areas of the prefrontal cortex (PFC) are involved in coordination of both memory and learning systems (e.g., ventromedial PFC inhibition of the amygdala in fear conditioning; orbitofrontal \& ventromedial PFC for reward and value processing) and undergoes the greatest amount of structural atrophy with age. The amygdala is involved in both fear conditioning in classical conditioning paradigms and the encoding and retrieval of emotional components of episodic memories.

Functional neuroimaging studies of declarative memory in healthy older adults have demonstrated age-related alterations in neural activity (see Cabeza, 2006; Giovanello \& Dew, 2015; Grady, 2008; Park \& Reuter-Lorenz, 2009; and Maillet \& Rajah, 2014 for a general discussion of relevant issues). Such alterations have taken the form of "under-recruitment" (i.e., failures to recruit specific brain regions to the same extent as young adults) or "non-selective recruitment" (i.e., recruitment of brain regions beyond those of young adults). Age-related functional alterations in declarative memory likely arise from age-dependent structural atrophy differences across distinct brain regions, including regions within the PFC (Gunning-Dixon \& Raz, 2003; Maillet \& Rajah, 2013; Pfefferbaum, Sullivan, Rosenbloom, Mathalon, \& Lim, 1998; Raz et al., 2005; Resnick, Pham, Kraut, Zonderman, \& Davatzikos, 2003) and MTL (Persson et al., 2006; Raz et al., 2005; Rodrigue \& Raz, 2004). Below, we define the declarative memory subsystems, specifically episodic and semantic memory, and then describe experimental behavioral studies and neuroimaging investigations of aging.

\section{Episodic memory}

Episodic memory enables individuals to recollect conscious experiences from their personal past (e.g., remembering what you ate for lunch yesterday). According to Tulving (1983), episodic memories are characterized by a sense of subjective awareness of having experienced remembered events in the past. To tap this 'recollective experience', Tulving developed the widely utilized remember/know paradigm, in which participants are initially presented with stimulus material and then asked to indicate whether the information is remembered (i.e., recollected with specific information) or known (i.e., retrieved with a sense of knowing 
something, yet void of any event details). This approach led to the proposal that two distinct mnemonic processes mediate episodic memory: recollection, as assessed with remember judgments, and familiarity, as indexed by know judgments (Yonelinas, 2002). However, such dual-process models of episodic memory have been consistently challenged by the view that episodic memory does not inherently rely on recollection and familiarity processes, but rather that episodic memories may be strong or weak (Wais, Squire, \& Wixted, 2010).

Cognitive aging studies, including those that have utilized the remember/know paradigm or assessed the status of recollection and familiarity in aging (Anderson et al., 2008; Bastin \& Van der Linden, 2003; Davidson \& Glisky, 2002; Jacoby, 1999; Jennings \& Jacoby, 1993; NavehBenjamin et al., 2009; Spencer \& Raz, 1995; Yonelinas, 2002), have shown that older adults do not perform as well as young adults on tests of episodic memory. Several prominent theories have been proposed to account for age-related episodic memory declines, including general slowing (Salthouse, 1996), reductions in attentional-resources (Craik \& Byrd, 1982), dysfunction of inhibitory processes (Hasher, Lustig, \& Zacks, 2007), and changes in sensory and perceptual abilities (Lindenberger \& Baltes, 1994). While these influential theories attempt to explain the range of cognitive changes observed in adulthood, two theoretical views have been proposed to explicitly account for age-related changes in episodic memory (for review see Giovanello \& Dew, 2015). More specifically, the binding deficit view asserts that older adults have a fundamental deficit in linking or integrating the separate elements of an episode (Bayen, Phelps, \& Spaniol, 2000; Burke \& Light, 1981; Chalfonte \& Johnson, 1996; Lyle, Bloise, \& Johnson, 2006; Mitchell, Johnson, Raye, \& D’Esposito, 2000; Naveh-Benjamin, 2000; Ryan, Leung, Turk-Browne, \& Hasher, 2007), while the control deficit view suggests that older adults experience more generalized declines in cognitive control processes (Anderson \& Craik, 2000; Craik, 1986; Craik \& Byrd, 1982; Jennings \& Jacoby, 1993; Light, Prull, LaVoie, \& Healy, 2000; Moscovitch \& Winocur, 1995; Smith, Park, Earles, Shaw, \& Whiting, 1998), such as the strategic manipulation, organization, or evaluation of contextual attributes and the intentional retrieval of associative or relational information (Dew \& Giovanello, 2010). 
There is accumulating evidence suggesting that age-related declines in episodic memory are linked to structural and functional changes in the PFC. The frontal aging hypothesis proposes that age-related episodic memory changes are primarily due to PFC dysfunction (Moscovitch \& Winocur, 1995; West, 1996). In support of this view, structural magnetic resonance imaging (MRI) studies of the aging brain consistently demonstrate frontal atrophy (Coffey et al., 1998; Convit et al., 2001; Cowell et al., 1994; Gur, Gunning-Dixon, Bilker, \& Gur, 2002; Raz et al., 1997). The frontal lobes show the steepest rate of age-related atrophy (Pfefferbaum et al., 1998; Raz et al., 2005; Resnick et al., 2003) and, critically, this atrophy has been shown to correspond to cognitive changes (Gunning-Dixon \& Raz, 2003; Maillet \& Rajah, 2013). Additional evidence linking age-related episodic deficits with PFC dysfunction comes from functional neuroimaging studies showing age-related decreases in PFC activity during tasks of episodic memory. Agerelated decreases in PFC activity have been observed during both encoding (Dennis et al., 2008; Kim \& Giovanello, 2011; Mitchell et al., 2000; Iidaka et al., 2001) and retrieval (Cabeza, Anderson, Locantore, \& McIntosh, 2002; Giovanello \& Schacter, 2012) of episodic information.

There is also evidence suggesting that age-related episodic memory declines are linked to MTL structure and function. The MTL has a hierarchical organization, whereby information from sensory association cortices are channeled through the parahippocampal region (e.g., perirhinal and parahippocampal cortices), to the entorhinal cortex, and on to the hippocampus (Squire \& Zola-Morgan, 1991). These memory structures undergo age-related atrophic changes, with significant atrophy observed in the hippocampus and minimal change in the entorhinal cortex (Raz et al., 2005) - although shrinkage of the entorhinal cortex has been shown to correlate with poorer memory performance, while changes in the PFC and hippocampus have not (Rodrigue \& Raz, 2004). Persson and colleagues (2006) reported reduced hippocampal volume in a group of older adults whose episodic memory performance declined over time compared to that of a group whose memory performance remained stable. Relatedly, Yonelinas and colleagues (2007) showed that reductions in hippocampal volume resulted in decreased recollection of episodic memories. More recently, Braskie, Small, and Bookheimer (2009) examined the relationship between entorhinal cortex thickness and functional MRI (fMRI) activity during an associative verbal (word pair) memory task. The results showed that participants with a thicker left entorhinal cortex had greater activation in anterior cingulate and medial frontal regions during 
memory retrieval, but not encoding. This result was independent of hippocampal volume. Finally, de Chastelaine and colleagues (2011) investigated the effects of age, memory performance, and callosal integrity on the neural correlates of successful episodic encoding. Participants in the study were scanned while making judgments about word pairs. A relationship was found between encoding trials that were subsequently remembered and activity in left inferior frontal gyrus, as well as bilateral hippocampus. Negative effects (i.e., greater activity for forgotten than remembered trials) were observed in default mode network regions (e.g., medial brain regions) for young adults, but were reversed in the old - and that reversal correlated negatively with memory performance.

The relationship between age-related episodic memory deficits and MTL atrophy is also supported by fMRI studies demonstrating age-related reductions in MTL activity during encoding (Mitchell et al., 2000; Daselaar, Veltman, Rombouts, Raaijmakers, \& Jonker, 2003; Dennis et al., 2008) and retrieval (Daselaar, Fleck, Dobbins, Madden, \& Cabeza, 2006; Giovanello \& Schacter, 2012; Tsukiura \& Cabeza, 2008) of episodic information, particularly in the hippocampus. For example, Giovanello \& Schacter (2012) hypothesized that healthy older adults would show age-related changes in MTL recruitment when the experimental task required the retrieval of specific, detailed, relational information. In young adults, left posterior ventrolateral PFC and bilateral hippocampal activity was modulated by the extent to which the retrieval task depended on relational processing (i.e., activity was greater during retrieval of relation, relative to item, information). For older adults, in contrast, activity in these regions was equivalent for item memory and relational (associative) memory conditions, suggesting an agerelated change in the recruitment of ventrolateral PFC and hippocampal regions during retrieval of episodic information. In line with these findings, fMRI evidence has shown that aging reduces recollection-related hippocampal activity (Dennis, Kim, \& Cabeza, 2008; Morcom, Li, \& Rugg, 2007; but see Persson, Kalpouzos, Nilsson, Ryberg, \& Nyberg, 2010), yet enhances familiarityrelated activity in the perirhinal cortex (Daselaar, Fleck, Dobbins, Madden, \& Cabeza, 2006). 


\section{Semantic memory}

Semantic memory encompasses a wide range of information, including facts about the world, the meanings of words and concepts, and the names attached to people and objects. Both crosssectional and longitudinal studies indicate less age-related decline in semantic memory compared to episodic memory (e.g., Rönnlund, Nyberg, Bäckman, \& Nilsson, 2005; see Figure 2). At a processing level, semantic memories differ from episodic memories in that they may be retrieved without associated information about the context in which they were learned. Importantly, not all forms of semantic knowledge share the same properties. Some forms of knowledge may be acquired after a single exposure (e.g., knowledge that Boston is the capital of Massachusetts), whereas other forms may be gradually acquired across multiple repetitions (e.g., understanding the concept website). Additionally, semantic learning may involve establishing new associations between pre-existing representations in memory (e.g., learning that William Shakespeare wrote "Romeo and Juliet") or acquiring a new label for information already represented in memory (e.g., learning a foreign language). Finally, a new label and a novel set of properties may be linked to each other (e.g. learning the concept of a microbrew).

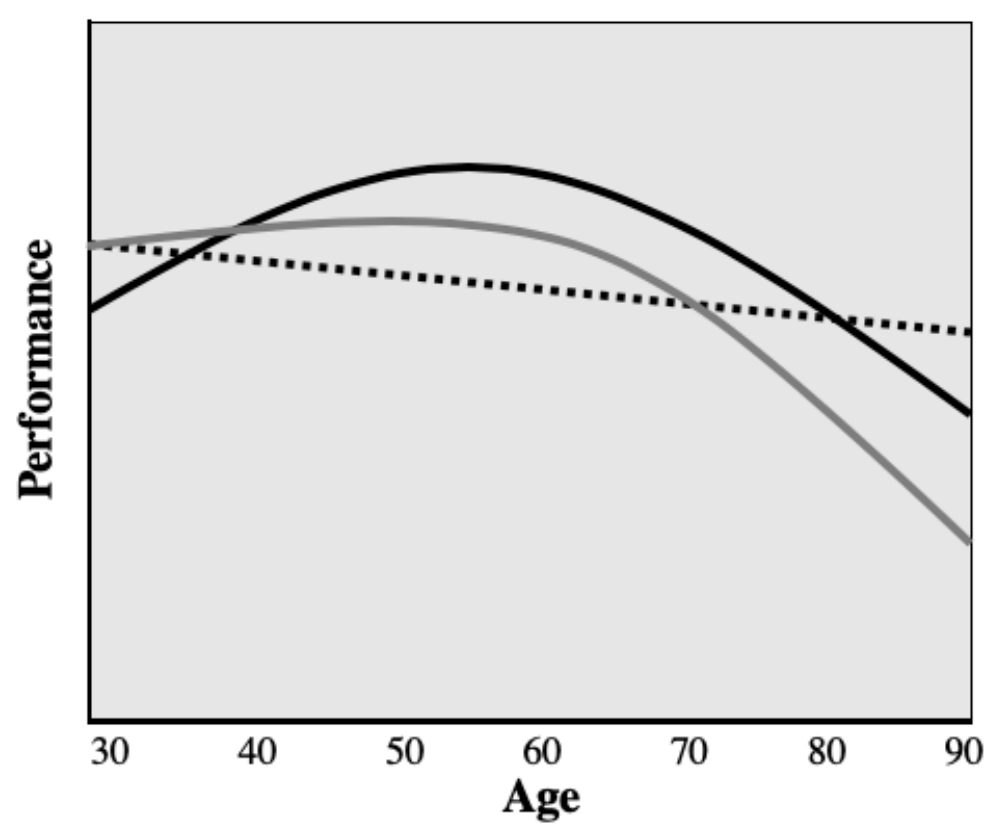

Declarative System

- Episodic Memory

- Semantic Memory

.. Nondeclarative System

Classical Conditioning

Priming/Perceptual Learning

Procedural Learning

Figure 2. Estimated aging trajectory of declarative and nondeclarative memory and learning systems. Although explicit memory and learning tasks have been able to successfully estimate 
the relative rates of maintenance and decline of declarative episodic and semantic memory performance in later life (adapted from Rönnlund et al., 2005), the use of implicit learning and memory tasks have not fully informed separate trajectories of the nondeclarative system with age. While components such as name recall, value processing, and task maintenance that rely on the prefrontal cortex undergo decline with age, processes dependent on the accumulation of world knowledge and slow, implicit procedural learning are generally maintained and strengthened throughout the lifetime - allowing for individual differences in successful compensation on memory and learning tasks (e.g., the use of explicit strategies).

Given the varied nature of semantic information and its accrual over the lifetime, behavioral aging studies have primarily focused on retrieval of semantic information using tests of picture naming, vocabulary, and text comprehension (Burke \& Shafto, 2008). Studies investigating agerelated changes in vocabulary knowledge and text comprehension have consistently reported that these measures are well preserved in aging and, in the case of vocabulary knowledge, improve over the adult life span (Alwin \& McCammon, 2001; Verhaeghen, 2003). Additionally, preserved semantic function in older adults has also been reported during semantic judgments (Little, Prentice, \& Wingfield, 2004) and semantic priming (Madden, Pierce, \& Allen, 1993). In contrast, one of the most frequent cognitive complaints among older adults is difficulty with finding words (Albert et al., 2009; Clark-Cotton, Williams, Goral, \& Obler, 2007; Mortensen, Meyer, \& Humphreys, 2006; Neumann, Obler, Gomes, \& Shafer, 2009). These naming difficulties have been confirmed in both cross-sectional (MacKay, Connor, Albert, \& Obler, 2002; Marien, Mampaey, Vervaet, Saerens, \& de Deyn, 1998) and longitudinal (Au et al., 1995; Barresi, Nicholas, Connor, Obler, \& Albert, 2000; Connor, Spiro, Obler, \& Albert, 2004; Goral, Spiro, Albert, Obler, \& Connor, 2007) studies. Although older adults complain of word-finding difficulties, not all studies have found age-related declines in naming. Moreover, determining when such age-related decreases in naming performance arise during the adult life span has been controversial. To investigate this issue, Verhaegen and Poncelet (2013) assessed picture-naming performance in participants at the ages of 25-35, 50-59, 60-69, and above 70 years of age. In addition to naming accuracy, naming latencies were assessed to reveal subtle naming difficulties. Importantly, to control for general slowing (as opposed to slowing specific to the naming task), participants were also given an odd/even judgment task to assess cognitive processing speed. The 
researchers reported that participants in their 50s showed decline in naming performance, reflected by an increase in naming latencies, while adults in their $60 \mathrm{~s}$ and their 70 s showed both a decrease in accuracy and an increase in latency. The increase in naming latencies remained significant even after controlling for odd/even judgment latencies, suggesting a specific decline in picture naming. Finally, to further assess the degradation of semantic knowledge, participants were tested with a synonym judgment task and the Pyramids and Palm Trees test (the latter task requires participants to identify pairings of conceptually related words or pictures). The results revealed semantic degradation in the group above 70 years old.

Neuroimaging studies have consistently shown activation in left prefrontal and temporal cortices during semantic retrieval. However, disagreement exists about the specific nature of the processes mediated by subregions within the PFC. One theoretical view proposes that the left inferior frontal gyrus (IFG), particularly the ventral region (BA47), is involved in semantic processing (Dapretto \& Bookheimer, 1999; Friederici, Meyer, \& von Cramon, 2000; Poldrack et al., 1999), while another theoretical views asserts that the left IFG has a domain-general role in selecting among competing candidates (Humphreys \& Gennari, 2014; January, Trueswell, \& Thompson-Schill, 2009; Moss et al., 2005; Schnur et al., 2009; Thompson-Schill, Bedny, \& Goldberg, 2005; Thompson-Schill, D’Esposito, Aguirre, \& Farah, 1997). The role of the left temporal cortex in semantic memory has been informed by patient-based and functional neuroimaging studies investigating the continuum of general semantic knowledge to knowledge of specific exemplars or items. For example, Tyler and colleagues (2011) suggest that naming at the specific level requires retrieval and integration of more detailed semantic information than at the domain-general level. That is, naming a picture at the domain-general level requires activation of item features only, whereas naming a picture at the specific level entails retrieval and integration of additional, more precise features. Tyler and colleagues have observed that patients with lesions to the anterior temporal lobes cannot reliably name exemplars (e.g., tiger) at the specific level, indicating that retrieval and integration of more detailed semantic information is impaired. Moreover, convergent evidence comes from fMRI studies in young adults in which greater activation in the anterior temporal lobes is observed with specific level naming than with domain level naming. 
As with episodic memory, age-related functional activity changes during semantic memory tasks have taken the form of "non-selective recruitment" (i.e., recruitment of brain regions engaged beyond those of young adults) resulting in reduced laterality, such that young adults may engage only the left PFC, while older adults activate the PFC bilaterally. Although debate exists about whether such age-related increase in right PFC activation reflect compensatory processes (Cabeza, Anderson, Locantore, \& McIntosh, 2002; Park \& Reuter-Lorenz, 2009; Peelle, Trojani, Wingfield, \& Grossman, 2010; Wierenga et al., 2008) or less efficient neural responses (Li, Lindenberger, \& Sikstrom, 2001; Park et al., 2004), both patterns have been observed in neural investigations of semantic memory and aging. Consistent with the compensation view, Wierenga et al. (2008) reported age-related increased functional activation of the right IFG associated with higher accuracy during picture naming, and Tyler and colleagues (2010) observed age-related increased activation in right inferior frontal cortex during a comprehension task, under conditions in which performance was matched between young and older adults. In contrast, agerelated increases right IFG activity have also been observed during poor performance. For example, during a semantic fluency task, Meinzer et al. (2009) found negative correlations between neural activity in the right IFG in older adults and the production of semantic exemplars. Likewise, Diaz and colleagues (2014) showed that older adults produced more errors than young adults on a phonological judgment task that required covert production of picture names and, although older adults exhibited greater activation than younger adults, this activity was not related to behavioral performance.

More recently, Zhuang and colleagues (2016) investigated the neural underpinnings of phonological and semantic retrieval in young and older adults using rhyme and semantic similarity judgment tasks. Although all participants responded faster and more accurately during the rhyme task compared to the semantic task, older adults demonstrated higher accuracy than young adults during semantic similarity judgments. Analysis of the fMRI data revealed no overall age-related differences, with bilateral IFG, bilateral supramarginal gyri, cingulate, and left superior temporal gyrus supporting performance. However, an interaction of age (young, old) and task (phonological, semantic) was observed during the semantic judgment task, with older adults showing greater activation than younger adults in left inferior frontal, bilateral posterior cingulate, and left fusiform regions. Taken together, these results indicate that 
at lower levels of task difficulty, older and younger adults engaged similar neural networks that benefited behavioral performance. However, as task difficulty increased during the semantic task, older adults relied more heavily on left hemisphere regions, as well as regions involved in perception and strategic monitoring. Zhuang et al. (2016) suggest that these results are consistent with the stability of language comprehension across the adult life span and illustrate how the preservation of semantic representations with age may influence performance during high task difficulty.

\section{Neural correlates of the nondeclarative system}

Brain regions most commonly associated with the nondeclarative system include the striatum for procedural and reinforcement learning, stimulus-relevant neocortical areas for priming and perceptual learning, and the amygdala and cerebellum for conditioning (see Figure 1; Squire \& Dede, 2015; Squire, 2004). More specifically, skill and reward-based learning depend on dopamine projections of value signals from the midbrain (e.g., substantia nigra and ventral tegmental area) to the striatum (Schultz 2013), which is divided into functionally distinct subregions (Smith \& Graybiel, 2013; Yin et al., 2009). The ventral striatum (e.g., nucleus accumbens, ventral caudate nucleus, and putamen) is associated with early learning and valuation processing in conjunction with medial PFC regions, while the dorsal striatum (e.g., dorsal caudate nucleus and putamen) supports overlearned behaviors through coordination with the dorsal PFC and motor regions (Haber \& Knutson, 2010; Haruno \& Kawato, 2006; Hiebert, Hampshire, Owen, Seergobin, \& MacDonald, 2014). Neural mechanisms of priming and perceptual learning involve attenuated cortical activity upon repetition of previously experienced stimuli and their associates (Schacter, Wig, \& Stevens, 2007). Facilitated processing has been attributed to stimulus-specific neural assemblies "sharpening" their responses for more efficient processing (Wiggs \& Martin, 1998), while the PFC appears to drive the efficiency of communication across regions (Schacter et al., 2007). Finally, with respect to classical conditioning, motor and emotion-based conditioning are distinct in their neural correlates. Motor conditioning relies on the cerebellum (e.g., delayed eyeblink task; Thompson \& Steinmetz, 2009), including simultaneous activation of the cerebellar cortex and its nuclei during learning acquisition (Thürling et al., 2015). In contrast, the amygdala is critically involved in classical conditioning involving arousal states such as threat (Bechara et al. 1995; LaBar, LeDoux, 
Spencer, \& Phelps, 1995; Morris, DeGelder, Weiskrantz, \& Dolan, 2001). The prefrontal cortex also plays a role in classical conditioning - for example, through inhibition of the amygdala when automatic defensive behaviors do not allow for escape from threat (Moscarello \& LeDoux, 2013).

Cross-sectional and longitudinal structural neuroimaging evidence shows age-related volume loss in all of the aforementioned brain regions, with considerable heterogeneity in the nature of change and some notable similarities to aging in the declarative memory system. For example, comparable age effects are observed for the amygdala and hippocampus (Fjell \& Walhovd, 2010). In an analysis of 883 adults from ages 18 to 93, Walhovd and colleagues (2011) found that the striatum and hippocampus age at approximately the same rate - but within the striatum some structures age faster (e.g., putamen, pallidum, accumbens) relative to others (e.g., caudate). The hippocampus and caudate are also associated with non-linear changes, but while shrinkage of the hippocampus appears to accelerate in late life, shrinkage of the caudate seems to decelerate (Fjell \& Walhovd, 2010; Walhovd et al., 2011; Raz et al., 2005; Raz, Ghisletta, Rodrigue, Kennedy, \& Lindenberger, 2010). Across brain regions, the cerebral cortex exhibits the greatest grey matter loss across adulthood and accelerating white matter loss in later life (Walhovd et al., 2011). However, grey matter volume in the occipital lobe (implicated in perceptual priming) appears to be relatively stable with age (Driscoll et al., 2009; Fjell \& Walhovd, 2010; Raz et al., 2010). Thus, age-related changes to macrostructure suggests that all forms of learning and memory are subject to age effects, and processing changes may be driven by the subregions within memory systems that are most vulnerable to age-related decline.

\section{Procedural and reinforcement learning}

The literature on age-related changes to procedure and reinforcement learning mechanisms has expanded greatly in recent years. Indeed, prior reviews of learning and memory in aging dedicated only small sections to the topic (Craik, 1994; Hoyer \& Verhaeghen, 2006; Lustig \& Flegal, 2008; Nilsson, 2003). This lack of attention reflected the low number of human studies and the general conclusion, based on limited findings, that these forms of procedural learning showed little age-related change. This seems odd in retrospect, as it had been known since the 1980s that the striatum played a critical role in feedback-based learning (Packard, Hirsh, \& 
White, 1989) and normal aging was associated with significant decline in striatal dopamine receptors (Severson, Marcusson, Winblad, \& Finch, 1982; Wong et al., 1984). Renewed interest in this topic coincided with the birth of neuroeconomics as a field of study, as researchers tried to understand if and how brain aging affects our ability to make value-based decisions (Eppinger, Hämmerer, \& Li, 2011).

Reinforcement learning yields habit-based behaviors that make up a significant part of our everyday decision making. Such behaviors arise from the slow building of associations between actions and their likely consequences through trial-and-error (Thorndike, 1911). Typical tasks involve stimuli with probabilistic associations to immediate choice outcomes (e.g., rewards, punishments). Learning results in higher selection rates for reward-predicting stimuli and/or lower selection rates of punishment-predicting stimuli over time. Most behavioral findings indicate that older adults maintain the ability to acquire adaptive behaviors through trial-anderror learning with probabilistic outcomes, but typically find declines in learning performance for older adults relative to young (Eppinger, Schuck, Nystrom, \& Cohen, 2013; Hämmerer, Li, Müller, \& Lindenberger, 2011; Lighthall, Gorlick, Schoeke, Frank, \& Mather, 2013; Wood, Busemeyer, Koling, Cox, \& Davis, 2005) - although age effects often depend on the precise metrics of performance or specific task conditions. Recent advances in cognitive neuroscience research have shed light on both the likely mechanisms of age-related change in procedural learning and sources of heterogeneity in the learning behavior of older adults. Much progress in this area of study is attributable to computational learning models, which allow for the examination of discrete learning components and their neural correlates. Functional imaging studies using these approaches can investigate how the brain processes action-based outcomes (e.g., rewards) according to valence and magnitude, integrates past reward histories into accurate expected values for states or situations, and then generates prediction errors when actual rewards differ from expected rewards (Niv, 2009; Schultz, Dayan, \& Montague, 1997; Sutton \& Barto, 1998).

In considering mechanisms of change to learning, one possibility is that aging negatively impacts the ability to respond to the positive and negative outcomes of our choices. Within the cortex, delivery of reward is consistently associated with activation in the orbitofrontal, ventromedial 
prefrontal, and anterior cingulate regions (Haber \& Knutson, 2010; Schultz, 2000). Extant research indicates that both simple reward detection and the representation of reward magnitude are preserved in healthy older adults. Responses to positive outcomes (e.g., rewards, gains) are generally maintained or may even increase with age in regions such as the medial PFC, anterior cingulate, and striatum in healthy aging (e.g., Dreher, Meyer-Lindenberg, Kohn, \& Berman, 2008; Samanez-Larkin et al., 2007; Schott et al., 2007). Neural mechanisms of responses to negative outcomes (e.g., punishments, losses) are less established (Schultz, 2017), but similar response patterns have been observed across younger and older adults in the anterior cingulate, inferior parietal cortex, dorsolateral PFC, insula, and putamen (Eppinger et al., 2013). Eppinger and colleagues (2013) also found age differences based on outcome valence, such that older adults showed reduced neural responses to gains but not losses in the ventromedial PFC. However, other studies have specifically tested for age-by-valence effects in this region and found no significant interaction (Samanez-Larkin et al., 2007; Samanez-Larkin, Worthy, Mata, McClure, \& Knutson, 2014). Notably, Samanez-Larkin and associates (2007) observed the maintenance of neural responses to positive and negative outcomes across and within different levels of magnitude, and in another investigation (Samanez-Larkin et al., 2014), observed increased response to gains in the anterior cingulate for older versus younger adults. These mixed results highlight the need for future research to further examine potential age-by-outcome valence interactions. However, consistencies across studies suggest that age-related change to simple outcome response is not the primary driver of age differences in reinforcement learning.

In contrast, age-related changes to the behavioral and neural correlates of value updating are frequently observed. When stimulus-outcome likelihoods are stable or explicitly stated, older adults' performance is often similar to that of younger adults, but relatively poorer when outcome likelihoods are probabilistic or involve reversal learning (Eppinger, Heekeren, \& Li, 2015; Eppinger, Kray, Mock, \& Mecklinger, 2008; Hämmerer et al., 2011; Lighthall et al., 2013; Mata, Josef, Samanez-Larkin, \& Hertwig, 2011; Mell et al., 2005; Pietschmann, Endrass, Czerwon, \& Kathmann, 2011; Samanez-Larkin et al., 2014; Van de Vijver, Ridderinkhof, \& de Wit, 2015; Weiler, Bellebaum, \& Daum, 2008). It is important to note that providing outcome contingencies, or making them very easy to learn, can effectively diminish or altogether eliminate the need for implicit learning and its neural mechanisms. As such, an environment 
where outcome likelihoods are uncertain or changing will increase the reliance on truly implicit procedural learning. Under such conditions, the representation of accurate expected values critically depends on predictor error signals for value updating (Chase, Kumar, Eickhoff, \& Dombrovski, 2015). These signals correspond to discrepancies between actual and expected rewards, with positive prediction errors (i.e., actual > expected) enhancing phasic dopamine neuron firing (Schultz, 2017). Further, functional imaging studies in humans, along with electrophysiological and lesion studies in animals, have shown that reward prediction error signals act on subject behavior via mesostriatal dopamine projections and the synaptic modification of cortical-striatal-midbrain networks (Chase et al., 2015; Eppinger et al., 2011).

Evidence that older adults are specifically impaired in value updating led to the hypothesis that age-related alterations to striatal prediction error signals cause deficits in reinforcement-based learning among older adults (Eppinger et al., 2011; Samanez-Larkin \& Knutson, 2015). Consistent with this hypothesis, fMRI studies of reinforcement learning have observed agerelated reductions in activation of the medial PFC and nucleus accumbens, corresponding to learning model-based reward prediction errors among older adults (Samanez-Larkin et al., 2014; Eppinger et al., 2013). Others have manipulated dopamine levels using L-DOPA in older adults to determine if increasing available dopamine can improve older adults' learning performance and restore their neural prediction error signal to the canonical form observed in young adults (Chowdhury et al., 2013). Chowdhury and colleagues (2013) found that L-DOPA had different effects on subgroups of older adults. While one subgroup performed at the level of younger adults on placebo and experienced a decrease in performance on L-DOPA $(n=17)$, the other subgroup experienced a boost in learning performance - bringing them up to the level of young adults when on the drug $(n=15)$. Critically, within the group who benefitted from L-DOPA, fMRI results revealed that the drug restored their reward prediction error signal in the ventral striatum. The impact of L-DOPA was specific to the expected value component of the prediction error (versus the reward response). In contrast, the subgroup of older adults who performed worse on L-DOPA appeared to have greater noise in their neural prediction error components when on the drug. Consistent with results in the former subgroup of older adults (worse performance on L-DOPA), a recent fMRI study demonstrated that older adults with reinforcement learning performance equal to younger adults had no age-related decline in striatal 
prediction error response to immediate feedback (Lighthall, Pearson, Huettel, \& Cabeza, 2018). Critically, however, the same group of older adults exhibited relatively diminished hippocampal prediction error signals that support learning from delayed feedback. Thus, striatally-mediated learning functions appear to be relatively well preserved in at least a subpopulation of highfunctioning older adults who nonetheless exhibit decline in hippocampally-mediated learning functions.

The findings above are consistent with earlier studies suggesting that trial-and-error learning from immediate feedback is well preserved in a large percentage of healthy older adults (Denburg et al., 2005; 2006) and studies finding no impact of aging on basic reward outcome responses (Dreher et al., 2008; Samanez-Larkin et al., 2007; Schott et al., 2007). They also provide convincing evidence that age effects on habit development are driven by dopaminemediated alterations to expected value representations in the striatum. In addition, a current hypothesis proposes that age effects on reward learning stem from declines in the structural integrity of frontostriatal white matter connections that support corrections to reward predictions (Samanez-Larkin \& Knutson, 2015). Consistent with this proposal, a study of age effects on reward learning using diffusion tensor imaging found that age was associated with declines in the coherence of frontostriatal pathways (i.e., connections from thalamus to medial PFC and medial PFC to nucleus accumbens; Samanez-Larkin, Levens, Perry, Dougherty, \& Knutson, 2012). Furthermore, age differences in reward learning were fully explained by white matter coherence within these specific tracts.

Given that reinforcement learning and procedural skill learning share both neural mechanisms (e.g., striatum) and process features (e.g., effects of outcome probabilities, magnitudes, variabilities, and delays; Fu \& Anderson, 2006), one may expect similar trajectories of agerelated changes as behaviors go from processing recurrent choices to developing complex skills. Indeed, as with reinforcement learning, the overall ability to learn new skills is maintained into old age (Ren, Wu, Chan, \& Yan, 2013), while learning rates and skill performance levels are typically lower in older adults compared with younger and middle-aged adults (Durkina, Prescott, Furchtgott, Cantor, \& Powell, 1995; King, Fogel, Albouy, \& Doyon, 2013; Rodrigue, Kennedy, \& Raz, 2005; Voelcker-Rehage, 2008). 
Like simple reward learning, individual differences and task-related factors can affect both the existence and magnitude of age differences in procedural skill learning, as well as the specific performance measure on which age effects are observed. Motor sequence learning tasks (e.g., serial reaction time) are commonly used in laboratory studies to index skill learning and performance. Motor sequence learning tasks involve the development of smooth, effortless movements from repeated sequence training. For instance, in the classic serial reaction time task, button-response sequences are implicitly learned by following a pattern of visual cues over many trials. A key finding from motor sequence learning studies is that the initial sequence learning abilities are relatively intact in healthy older adults (King et al., 2013), as well as in patients with damage to the medial temporal lobes (Van Halteren-Van Tilborg, Scherder, \& Hulstijn, 2007). Importantly, similar age-related changes to skill learning and performance are also observed for motor tasks that do not involve sequences (e.g., force production, simple tracking; VoelckerRehage, 2008) as well as skill learning tasks that do not require a motor response (e.g., mirrorreversed reading; Durkina et al., 1995).

For simple skills, older adults may exhibit performance levels similar to younger adults; however, as task complexity increases, initial learning rates are reduced in older adults (King et al., 2013). For example, one study found that older adults performed worse under dual-task versus single-task conditions during sequence learning (Gamble, Howard, \& Howard, 2014). Yet, in the same study, post-learning probes indicated equivalent performance among older adults for sequences learned across conditions. Thus, executive demands during motor sequence learning may sometimes suppress the expression of learning in older adults, rather than impairing learning itself. Another factor mediating age effects is whether explicit knowledge is involved in the motor sequence-learning task. For example, when older adults are told that a motor sequence learning task has an embedded sequence and that learning the sequence can help them respond more quickly, they show poorer learning relative to older adults without this explicit knowledge (Howard \& Howard, 2001). Notably, younger adults' sequence learning is unaffected or enhanced by explicit knowledge (Willingham \& Goedert-Eschmann, 1999; Howard \& Howard, 2001; Willingham, Salidis, \& Gabrieli, 2002). With respect to post-learning performance, age is associated with poorer consolidation of motor memories (e.g., during sleep; Spencer, Gouw, \& 
Ivry, 2007; Wilson, Baran, Pace-Schott, Ivry, \& Spencer, 2012) and poorer adaptation to sensorimotor perturbations. Older adults' difficulty in adapting to changes in required motor patterns (i.e., motor adaptation) appears to be most pronounced immediately at the change initiation (King et al., 2013), and this deficit has been linked to reduced explicit awareness of pattern changes among older adults (Heuer \& Hegele, 2008). Thus, again, aging is associated with a reduced ability to use explicit knowledge to benefit procedural learning.

Among the most direct evidence linking age-related changes to the brain and changes to skill learning are findings showing decreased putamen activation among older adults during the late phase of learning in serial reaction tasks and altered patterns of PFC activation during learning (Aizenstein et al., 2006). Correspondingly, while reduced reaction time from early to late learning has been associated with decreasing MTL activation and increasing caudate activation in young adults, older adults exhibit associated increasing activation in both regions (Rieckmann, Fischer, \& Bäckman, 2010). Such findings may reflect age-related compensation in the MTL; however, more conclusive support for this interpretation requires age comparisons of MTL activation with trial-level performance measures (e.g., slow vs. fast reaction-time trials within subjects; Cabeza \& Dennis, 2013). Other critical findings include that lateral PFC and caudate volumes predict skill learning performance, but lateral PFC volumes change more with aging and are more predictive of skill learning in older compared with younger adults (Kennedy \& Raz, 2005). Together, these findings suggest that age-related changes to the basal ganglia and its connections to the PFC may be responsible for decline in simple habit and skill learning with age. Large-scale age differences observed in motor adaptation, more complex learning tasks, and procedural learning with "contamination" from explicit processing are likely due to age-related changes in the MTL and PFC.

\section{Priming and perceptual learning}

Repetition priming, also known simply as "priming", involves facilitated processing of previously experienced items or associates of those items (Squire \& Dede, 2015). Experienced information may be perceptual or conceptual and individuals need not be aware that the stimulus previously occurred, although processing may be affected by conscious awareness (Roediger \& McDermott, 1993). Typical priming tasks involve the presentation of words or pictures followed 
by a delay and then a second "unrelated" task. The second task includes primed material or associates as potential response options and such responses are more readily produced, as indicated by speed, accuracy, and response bias. Priming has been linked to "repetition suppression" effects, such that brain activation is reduced upon repetition of a stimulus in the neocortical regions initially involved in processing the stimulus or its associates (Wiggs \& Martin, 1998). The prevailing theory of repetition-related reductions in activation is that stimuliassociated neurons become more precise in their response with repeated exposure (Grill-Spector, Henson, \& Martin, 2006).

While a lack of age differences has been reported in numerous priming studies, careful reviews and meta-analyses indicate a decline in priming effects on perceptual and conceptual information in normal aging (Fleischman \& Gabrieli, 1998; La Voie \& Light, 1994; Ward, Berry, \& Shanks, 2013). Earlier research indicated that age differences in priming may be small or negligible depending on the specific task; however, a more recent report suggests that small but reliable age effects may have been obscured by low power and reliability in many priming studies (Ward et al., 2013). Correspondingly, event-related potentials (ERPs) and oscillatory responses to priming indicate attenuated repetition suppression effects in older compared with younger adults - even in the absence of behavioral differences (Sebastián \& Ballesteros, 2012).

Well-designed behavioral studies have revealed that age differences in the neural correlates of priming may relate to greater use of controlled encoding among younger adults. Gopie, Craik, and Hasher (2011) found that when individuals are told to ignore presented words and only respond to their text color, older adults show relatively greater implicit memory for primed words, but younger adults showed relatively greater explicit memory for primed words. The young adults' advantage for explicit memory disappeared when their attention was divided at encoding. This suggests that some age differences in priming and repetition suppression can be explained by deeper processing of "incidental" details by younger adults. With that said, the effectiveness of priming in older populations suggests cortical plasticity that may be leveraged to ameliorate declines in sensory processing via perceptual learning. Indeed, research shows that healthy older adults who engage in brief training sessions to improve visual discrimination (e.g., texture, motion) can retain benefits for at least several months (Bower, Watanabe, \& Andersen, 
2013; Andersen, Ni, Bower, \& Watanabe, 2010). These findings suggest that neural plasticity in early and later visual processing regions (Schwartz, Maquet, \& Frith, 2002) is maintained in late life.

\section{Classical conditioning}

Classical conditioning represents one of the most basic forms of learning - its functions and related mechanisms are conserved within mammals and are similar between vertebrates. In such tasks, a neutral stimulus (CS) is repeatedly paired with an unconditioned stimulus (US), the latter eliciting arousal and/or behavioral states prior to training. Learning is said to have occurred when the CS in isolation can elicit responses previously only attributed to the US. Across a range of condition paradigms, eyeblink conditioning (anticipatory blink from a CS) is more pronounced in younger versus older adults (Bellebaum \& Daum, 2004; Cheng, Faulkner, Disterhoft, \& Desmond, 2010; Knuttinen, Power, Preston, \& Disterhoft, 2001; Solomon, Pomerleau, Bennett, James, \& Morse, 1989). In contrast, aging impairs extinguishing of conditioned responses (Thürling et al., 2014). Cerebellar volume predicts eyeblink conditioned responses (WoodruffPak, Goldenberg, Downey-Lamb, Boyko, \& Lemieux, 2000) as well as the change in storage of conditioned responses with advancing age (Thürling et al., 2014). The hippocampus also plays a role in eyeblink conditioning, particularly when the CS and US are separated in time (e.g., "trace conditioning"; Cheng, Disterhoft, Power, Ellis, \& Desmond, 2008), but further work must be conducted to determine if age-related change to the hippocampus drives trace-conditioning deficits.

Age-related decline has also been observed for arousal-based conditioning. Contributing factors appear to include declines in autonomic responses to conditioned stimuli from middle age to late adulthood, along with lower levels of contingency awareness (LaBar, Cook, Torpey, \& WelshBohmer, 2004). In fact, simultaneously controlling for these two factors eliminated age differences in fear learning. Critically, middle aged and older adults exhibited lower autonomic response to the US during learning acquisition and lower orienting response to the CS. This age effect mirrors impaired older adults' reduced anticipatory physiological signal to losses in the Iowa Gambling Task (Denburg, Tranel, \& Bechara, 2005; Denburg, Recknor, Bechara, \& Tranel, 2006). The Iowa Gambling Task, developed by Bechara and colleagues (1994), requires 
feedback-based learning about card deck outcome probabilities over time and is commonly used to examine ventromedial PFC function and the integrated role of cognition and emotion in risky decision making. Thus, despite the fact that aging is associated with more "pure" implicit learning during classical conditioning, this is not enough to overcome learning deficits associated with age-related decline in autonomic signaling.

\section{Conclusions and future directions}

Taken together, the reviewed literature suggests unique trajectories of age-related change for different memory systems. Behavioral research indicates relatively greater stability in nondeclarative versus declarative forms of learning and memory, with a mid-life peak in declarative memory and more accelerated decline in episodic versus semantic memory (Figure 2). Age-related changes in the neural mechanisms of these memory systems likewise suggests generally greater decline in episodic relative to semantic and nondeclarative memory. Notably, however, there is currently a dearth of research comparing trajectories of age-related changes to different forms of nondeclarative memory and their neural correlates. Additional research is required to determine the precise rate and nature of change to different types of nondeclarative memory in aging.

Before closing, it is important to note that focal lesion studies strongly suggest independence of declarative and nondeclarative memory (Knowlton, Mangels, \& Squire, 1996; Packard et al., 1989), but accumulating evidence points to interactions between systems (e.g., Shohamy \& Wagner, 2008; Poldrack, Clark, Pare-Blagoev, \& Shohamy, 2001; Wimmer, Braun, Daw, \& Shohamy, 2014; Lee, Shimojo, \& O’Doherty, 2014). The latter studies involve innovative designs and analytic methods that allow for examination of memory mechanism interactions across systems and have not yet been applied to investigate age-related changes. Indeed, very few studies to date have directly compared age-related changes to the neural mechanisms of declarative and nondeclarative memory systems in the same participants (e.g., Dennis \& Cabeza, 2011; Lighthall et al., 2018). The available findings suggest that uncontrolled crossover between memory systems may be more common in older adults due to age related dedifferentiation of neural networks (Park \& Reuter-Lorenz, 2009), but these conclusions require additional evidence. 
Further, the degree to which classic nondeclarative tasks represent "pure" unconscious processing has been called into question (LeDoux, 2014; Nilsson, 2003). This chapter included several examples of porous boundaries between systems. Thus, while age differences generally decrease as limitations on explicit processing increase, younger adults can utilize structures and functions of the declarative system to their advantage in many classic nondeclarative tasks. Situations that allow for crossover from explicit to implicit processing are likely to increase observed age differences in learning and memory performance and benefit only the most cognitively fit older adults. As such, while this chapter largely highlighted age effects on learning and memory within traditional memory-system boundaries, a frontier in the cognitive neuroscience of aging is emerging at their intersections. 


\section{References}

Aizenstein, H. J., Butters, M. A., Clark, K. A., Figurski, J. L., Stenger, V. A., Nebes, R. D., ... \& Carter, C. S. (2006). Prefrontal and striatal activation in elderly subjects during concurrent implicit and explicit sequence learning. Neurobiology of Aging, 27(5), 741751.

Albert, M. L., Spiro, A., Sayers, K. J., Cohen, J. A., Brady, C. B., Goral, M., \& Obler, L. K. (2009). Effects of health status on word finding in aging. Journal of the American Geriatrics Society, 57, 2300-2305.

Alwin, D. F. \& McCammon, R. J. (2001). Aging, cohorts, and verbal ability. Journal of Gerontology: Series B, 56, S151-S161.

Andersen, G. J., Ni, R., Bower, J. D., \& Watanabe, T. (2010). Perceptual learning, aging, and improved visual performance in early stages of visual processing. Journal of Vision, 10(13), 4-4.

Anderson, N. D. \& Craik, F. I. M. (2000). Memory in the aging brain. In E. Tulving \& F. I. M. Craik (Eds.), The Oxford handbook of memory. New York, NY: Oxford University Press.

Anderson, N. D., Ebert, P. L., Jennings, J. M., Grady, C. L., Cabeza, R., \& Graham, S. J. (2008). Recollection- and familiarity-based memory in healthy aging and amnestic mild cognitive impairment. Neuropsychology, 22, 177-187.

Au, R., Joung, P., Nicholas, M., Obler, L. K., Kass, R., \& Albert, M. L. (1995). Naming ability across the adult life span. Aging and Cognition, 2(1), 300-311.

Barresi, B., Nicholas, M., Connor, L. T., Obler, L. K., \& Albert, M. L. (2000). Semantic degradation and lexical access in age-related naming failures. Aging, Neuropsychology, and Cognition, 7(3), 169-178.

Bastin, C. \& Van der Linden, M. (2003). The contribution of recollection and familiarity to recognition memory: A study of the effects of test format and aging. Neuropsychology, $17,14-24$.

Bayen, U. J., Phelps, M. P., \& Spaniol, J. (2000). Age-related differences in the use of contextual information in recognition memory: A global matching approach. Journals of Gerontology: Series B, 55, 131-141. 
Bechara, A., Damasio, A. R., Damasio, H., Anderson, S. W. (1994). Insensitivity to future consequences following damage to human prefrontal cortex. Cognition, 50, 7-15.

Bechara, A., Tranel, D., Damasio, H., Adolphs, R., Rockland, C., \& Damasio, A. R. (1995). Double dissociation of conditioning and declarative knowledge relative to the amygdala and hippocampus in humans. Science, 1115-1118.

Bellebaum, C., \& Daum, I. (2004). Effects of age and awareness on eyeblink conditional discrimination learning. Behavioral neuroscience, 118(6), 1157-1165.

Bower, J. D., Watanabe, T., \& Andersen, G. J. (2013). Perceptual learning and aging: Improved performance for low-contrast motion discrimination. Frontiers in Psychology, 4(66), 1-7.

Braskie, M. N., Small, G. W., \& Bookheimer, S. Y. (2009). Entorhinal cortex structure and functional MRI response during an associative verbal memory task. Human Brain Mapping, 30, 3981-3992.

Buckner, R. L. (2003). Functional-anatomic correlates of control processes in memory. The Journal of Neuroscience, 23, 3999-4004.

Burke, D. M. \& Light, L. (1981). Memory and aging: The role of retrieval processes. Psychological Bulletin, 90, 513-514.

Burke, D. M. \& Shafto, M. A. (2008). Language and aging. In F. I. M. Craik \& T. A. Salthouse (Eds.), The handbook of aging and cognition (3 ${ }^{\text {rd }}$ ed., pp. 373-443). New York, NY: Psychology Press.

Brewer, J. B., Zhao, Z., Desmond, J. E., Glover, G. H., and Gabrieli, J. D. E. (1998). Making memories: Brain activity that predicts how well visual experience will be remembered. Science, 281, 1185-1187.

Cabeza, R. (2006). Prefrontal and medial temporal contributions to relational memory in young and older adults. In D. Zimmer, A. Mecklinger, \& U. Lindenberger (Eds.), Binding in human memory: A neurocognitive approach (pp. 595-626). New York, NY: Oxford University Press.

Cabeza, R., Anderson, N. D., Locantore, J. K., \& McIntosh, A. R. (2002). Aging gracefully: Compensatory brain activity in high-performing older adults. Neuroimage, 17, 13941402. 
Cabeza, R. \& Dennis, N. A. (2013). Frontal lobes and aging: Deterioration and compensation. In D. T. Stuss \& R. T. Knight (Eds.), Principles of frontal lobe function ( $2^{\text {nd }}$ ed., pp. 628652). New York, NY, Oxford University Press.

Chalfonte, B. L. \& Johnson, M. K. (1996). Feature memory and binding in young and older adults. Memory and Cognition, 24, 403-16.

Chase, H. W., Kumar, P., Eickhoff, S. B., \& Dombrovski, A. Y. (2015). Reinforcement learning models and their neural correlates: An activation likelihood estimation meta-analysis. Cognitive, Affective, \& Behavioral Neuroscience, 15(2), 435-459.

Cheng, D. T., Disterhoft, J. F., Power, J. M., Ellis, D. A., \& Desmond, J. E. (2008). Neural substrates underlying human delay and trace eyeblink conditioning. Proceedings of the National Academy of Sciences, 105(23), 8108-8113.

Cheng, D. T., Faulkner, M. L., Disterhoft, J. F., \& Desmond, J. E. (2010). The effects of aging in delay and trace human eyeblink conditioning. Psychology and Aging, 25(3), 684-690.

Chowdhury, R., Guitart-Masip, M., Lambert, C., Dayan, P., Huys, Q., Düzel, E., \& Dolan, R. J. (2013). Dopamine restores reward prediction errors in old age. Nat Neurosci, 16:648653. doi:10.1038/nn.3364 pmid:23525044

Clark-Cotton, M. R., Williams, R. K., Goral, M., \& Obler, L. K. (2007). Language and communication in aging. In J. E. Birren (Ed.), Encyclopedia of gerontology: Age, aging, and the aged (2n ed., pp. 1-8). London, England: Elsevier.

Coffey, J. F., Lucke, J. A., Saxton, G., Ratcliff, L. J., Unitas, B., Billing, B., \& Byran, R. N. (1998). Sex differences in brain imaging. Archives of Neurology, 55, 169-179.

Connor, L. T., Spiro, A., Obler, L. K., \& Albert, M. L. (2004). Change in object naming ability during adulthood. The Journals of Gerontology: Series B, 59(5), 203-209.

Convit, A., Wolf, O. T., de Leon, M. J., Patalinjug, M., Kandil, E., Caraos, C., Scherer, A., Saint Louis, L. S., \&, Cancro, R. (2001).Volumetric analysis of the prefrontal regions: Findings in aging and schizophrenia. Psychiatry Research, 107, 61-73.

Cowell, P. E., Turetsky, B. T., Gur, R. C., Grossman, R. I., Shtasel, D. L., \& Gur, R. E. (1994). Sex differences in aging of the human frontal and temporal lobe. Journal of Neuroscience, $14,4748-4755$.

Craik, F.I.M. (1986). A functional account of age differences in memory. In F. Klix \& H.

Hagendorf (Eds.), Human memory and cognitive capabilities, mechanisms, and 
performances (pp. 409-422). North Holland, The Netherlands: Elsevier.

Craik, F. I. M. (1994). Memory changes in normal aging. Current Directions in Psychological Science, 3(5), 155-158.

Craik, F. I. M. \& Byrd, M. (1982). Aging and cognitive deficits: The role of attentional resources. In F. I. M. Craik \& S. Trehub (Eds.). Aging and cognitive processes (pp. 191211). New York, NY: Plenum Press.

Dapretto, M. \& Bookheimer, S. Y. (1999). Form and content: Dissociating syntax and semantics in sentence comprehension. Neuron, 24, 427-432.

Daselaar, S. M., Fleck, M. S., Dobbins, I. G., Madden, D. J., \& Cabeza, R. (2006). Effects of healthy aging on hippocampal and rhinal memory functions: An event-related fMRI study. Cerebral Cortex, 16, 1771-82.

Daselaar, S. M., Veltman, D. J., Rombouts, S. A., Raaijmakers, J. G., \& Jonker, C. (2003). Deep processing activates the medial temporal lobe in young but not in older adults. Neurobiology of Aging, 24,1005-11.

Davidson, P. S. \& Glisky, E. L. (2002). Neuropsychological correlates of recollection and familiarity in normal aging. Cognitive, Affective, \& Behavioral Neuroscience, 2, 174186.

de Chastelaine, M., Wang, T. H., Minton, B., Muftuler, L. T., and Rugg, M. D. (2011). The effects of age, memory performance, and collosal integrity on the neural correlates of successful associative encoding. Cerebral Cortex, 21, 2166-76.

Denburg, N. L., Tranel, D., \& Bechara, A. (2005). The ability to decide advantageously declines prematurely in some normal older persons. Neuropsychologia, 43(7), 1099-1106.

Denburg, N. L., Recknor, E. C., Bechara, A., \& Tranel, D. (2006). Psychophysiological anticipation of positive outcomes promotes advantageous decision-making in normal older persons. International Journal of Psychophysiology, 61(1), 19-25.

Dennis, N. A., \& Cabeza, R. (2011). Age-related dedifferentiation of learning systems: An fMRI study of implicit and explicit learning. Neurobiology of Aging, 32(12), 17-30.

Dennis, N. A., Hayes, S. M., Prince, S. E., Madden, D. J., Huettel, S. A., \& Cabeza, R. (2008). Effects of aging on the neural correlates of successful item and source memory encoding. Journal of Experimental Psychology: Learning, Memory, and Cognition, 34, 791-808.

Dennis, N. A., Kim, H., \& Cabeza R. (2008). Age-related differences in brain activity during true 
and false memory retrieval. Journal of Cognitive Neuroscience, 20(8), 1390-402.

Dew, I. T. Z. \& Giovanello, K. S. (2010). Differential age effects for implicit and explicit associative memory. Psychology and Aging, 25, 911-921.

Diaz, M. T., Johnson, M. A., Burke, D. M., \& Madden, D. J. (2014). Age-related differences in the neural bases of phonological and semantic processes. Journal of Cognitive Neuroscience, 26, 2798-811.

Dreher, J. C., Meyer-Lindenberg, A., Kohn, P., \& Berman, K. F. (2008). Age-related changes in midbrain dopaminergic regulation of the human reward system. Proceedings of the National Academy of Sciences, 105(39), 15106-15111.

Driscoll, I., Davatzikos, C., An, Y., Wu, X., Shen, D., Kraut, M., \& Resnick, S. M. (2009). Longitudinal pattern of regional brain volume change differentiates normal aging from MCI. Neurology, 72(22), 1906-1913.

Durkina, M., Prescott, L., Furchtgott, E., Cantor, J., \& Powell, D. A. (1995). Performance but not acquisition of skill learning is severely impaired in the elderly. Archives of Gerontology and Geriatrics, 20(2), 167-183.

Eichenbaum, H., Yonelinas, A. P., \& Ranganath, C. (2007). The medial temporal lobe and recognition memory. Annual Review of Neuroscience, 30, 123-152.

Eppinger, B., Hämmerer, D., \& Li, S. C. (2011). Neuromodulation of reward-based learning and decision making in human aging. Annals of the New York Academy of Sciences, 1235(1), 1-17.

Eppinger, B., Heekeren, H. R., \& Li, S. C. (2015). Age-related prefrontal impairments implicate deficient prediction of future reward in older adults. Neurobiology of Aging, 36(8), 23802390.

Eppinger, B., Kray, J., Mock, B., \& Mecklinger, A. (2008). Better or worse than expected? Aging, learning, and the ERN. Neuropsychologia, 46(2), 521-539.

Eppinger, B., Schuck, N. W., Nystrom, L. E., \& Cohen, J. D. (2013). Reduced striatal responses to reward prediction errors in older compared with younger adults. Journal of Neuroscience, 33(24), 9905-9912.

Fjell, A. M., \& Walhovd, K. B. (2010). Structural brain changes in aging: Courses, causes and cognitive consequences. Reviews in the Neurosciences, 21(3), 187-222. 
Fleischman, D. A. \& Gabrieli, J. D. (1998). Repetition priming in normal aging and Alzheimer's disease: A review of findings and theories. Psychology and Aging, 13(1), 88.

Friederici, A. D., Meyer, M., \& von Cramon, D. Y. (2000). Auditory language comprehension: An event-related fMRI study on the processing of syntactic and lexical information. Brain and Language, 75, 289-300.

Fu, W. T. \& Anderson, J. R. (2006). From recurrent choice to skill learning: A reinforcementlearning model. Journal of Experimental Psychology: General, 135(2), 184.

Gabrieli, J. D. E., Brewer, J. B., Desmond, J. E., \& Glover, G. H. (1997). Separate neural bases of two fundamental memory processes in the human medial temporal lobe. Science, 276, 264-266.

Gamble, K. R., Howard Jr., J. H., \& Howard, D. V. (2014). Does a simultaneous memory load affect older and younger adults' implicit associative learning? Aging, Neuropsychology, and Cognition, 21(1), 52-67.

Giovanello, K. S. \& Dew, I. T. Z. (2015). Relational memory and its relevance to aging. In D. R. Addis, M. Barense, \& A. Duarte (Eds.), The Wiley handbook on the cognitive neuroscience of human memory (pp. 371-392). Hoboken, NJ: John Wiley \& Sons, Ltd.

Giovanello, K. S. \& Schacter, D. L. (2012). Reduced specificity of hippocampal and posterior ventrolateral prefrontal activity during relational retrieval in normal aging. Journal of Cognitive Neuroscience, 24, 159-170.

Gopie, N., Craik, F. I., \& Hasher, L. (2011). A double dissociation of implicit and explicit memory in younger and older adults. Psychological Science, 22(5), 634-640.

Goral, M., Spiro, A. I., Albert, M. L., Obler, L. K., \& Connor, L. T. (2007). Change in lexical skills in adulthood: Not a uniform decline. Mental Lexicon, 2, 215-238.

Grady, C. L. (2008). Cognitive neuroscience of aging. Annual Review of the New York Academy of Sciences, 1124, 127-144.

Grill-Spector, K., Henson, R., \& Martin, A. (2006). Repetition and the brain: Neural models of stimulus-specific effects. Trends in Cognitive Sciences, 10(1), 14-23.

Gunning-Dixon, F. M. \& Raz, N. (2003). Neuroanatomical correlates of selected executive functions in middle-aged and older adults: A prospective MRI study. Neuropsychologia, 4, 1929-41.

Gur, R. C., Gunning-Dixon, F., Bilker, W. B., and Gur, R. E. (2002). Sex differences in temporo- 
limbic and frontal brain volumes of healthy adults. Cerebral Cortex, 12, 998-1003.

Haber, S. N. \& Knutson, B. (2010). The reward circuit: Linking primate anatomy and human imaging. Neuropsychopharmacology, 35(1), 4-26.

Hämmerer, D., Li, S. C., Müller, V., \& Lindenberger, U. (2011). Life span differences in electrophysiological correlates of monitoring gains and losses during probabilistic reinforcement learning. J. Cognitive Neuroscience, 23(3), 579-592.

Haruno, M. \& Kawato, M. (2006). Heterarchical reinforcement-learning model for integration of multiple cortico-striatal loops: fMRI examination in stimulus-action-reward association learning. Neural Networks, 19(8), 1242-1254.

Hasher, L., Lustig, C., \& Zacks, R. T. (2007). Inhibitory mechanisms and the control of attention. In A. R. A. Conway, C. Jarrold, M. J. Kane, A. Miyake, \& J. N. Towes (Eds.), Variation in working memory (pp. 227-249). New York, NY: Oxford University Press.

Heuer, H. \& Hegele, M. (2008). Adaptation to visuomotor rotations in younger and older adults. Psychology and Aging, 23(1), 190.

Hiebert, N. M., Vo, A., Hampshire, A., Owen, A. M., Seergobin, K. N., \& MacDonald, P. A. (2014). Striatum in stimulus-response learning via feedback and in decision making. Neuroimage, 101, 448-457.

Howard, D. V., \& Howard, J. H. (2001). When it does hurt to try: Adult age differences in the effects of instructions on implicit pattern learning. Psychonomic Bulletin \& Review, 8(4), 798-805.

Hoyer, W. J. \& Verhaeghen, P. (2006). Memory aging. In J. E. Birren \& K. W. Schaire (Eds.), Handbook of the psychology of aging (pp. 209-232). Amsterdam, Netherlands: Elsevier. Humphreys, G. F. \& Gennari, S. P. (2014). Competitive mechanisms in sentence processing: Common and distinct production and reading comprehension networks linked to the prefrontal cortex. Neuroimage, 1(84), 354-366.

Iidaka, T., Sadato, N., Yamada, H., Murata, T., Omori, M., \& Yonekura, Y. (2001). An fMRI study of the functional neuroanatomy of picture encoding in younger and older adults. Brain Research: Cognitive Brain Research, 11, 1-11.

Jacoby, L. L. (1999). Ironic effects of repetition: Measuring age-related differences in memory. Journal of Experimental Psychology: Learning, 25, 3-22.

January, D., Trueswell, J. C., \& Thompson-Schill, S. L. (2009). Co-localization of stroop and 
syntactic ambiguity resolution in Broca's area: Implications for the neural basis of sentence processing. Journal of Cognitive Neuroscience, 21, 2434-2444.

Jennings, J. M. \& Jacoby, L. L. (1993). Automatic versus intentional uses of memory: Aging, attention, and control. Psychology and Aging, 8, 283-293.

Kennedy, K. M. \& Raz, N. (2005). Age, sex and regional brain volumes predict perceptualmotor skill acquisition. Cortex, 41(4), 560-569.

Kim, S. Y. \& Giovanello, K. S. (2011). The effects of attention on age-related memory deficits: fMRI evidence from a novel attentional manipulation. Journal of Cognitive Neuroscience, 23, 3637-56.

King, B. R., Fogel, S. M., Albouy, G., \& Doyon, J. (2013). Neural correlates of the age-related changes in motor sequence learning and motor adaptation in older adults. Frontiers in Human Neuroscience, 7, 142.

Knowlton, B. J., Mangels, J. A., \& Squire, L. R. (1996). A neostriatal habit learning system in humans. Science, 273(5280), 1399-1402.

Knuttinen, M. G., Power, J. M., Preston, A. R., \& Disterhoft, J. F. (2001). Awareness in classical differential eyeblink conditioning in young and aging humans. Behavioral Neuroscience, 115(4), 747-757.

LaBar, K. S., Cook, C. A., Torpey, D. C., \& Welsh-Bohmer, K. A. (2004). Impact of healthy aging on awareness and fear conditioning. Behavioral Neuroscience, 118(5), 905-915.

LaBar, K. S., LeDoux, J. E., Spencer, D. D., \& Phelps, E. A. (1995). Impaired fear conditioning following unilateral temporal lobectomy in humans. Journal of Neuroscience, 15(10), 6846-6855.

La Voie, D., \& Light, L. L. (1994). Adult age differences in repetition priming: A meta-analysis. Psychology and Aging, 9(4), 539-553.

LeDoux, J. E. (2014). Coming to terms with fear. Proceedings of the National Academy of Sciences, 111(8), 2871-2878.

Lee, S. W., Shimojo, S., \& O'Doherty, J. P. (2014). Neural computations underlying arbitration between model-based and model-free learning. Neuron, 81(3), 687-699.

Li, S. C., Lindenberger, U., \& Sikstrom, S. (2001). Aging cognition: From neuromodulation to representation. Trends in Cognitive Science, 5, 479-486.

Light, L. L., Prull, M. W., LaVoie, D. J. \& Healy, M. R. (2000). Dual-process theories of 
memory in old age. In T. J. Perfect \& E. A. Maylor (Eds.), Models of cognitive aging (pp. 238-300). New York, NY: Oxford University Press.

Lighthall, N. R., Gorlick, M. A., Schoeke, A., Frank, M. J., \& Mather, M. (2013). Stress modulates reinforcement learning in younger and older adults. Psychology and Aging, $28(1), 35-46$.

Lighthall, N. R., Pearson, J. M., Huettel, S. A., \& Cabeza, R. (2018). Feedback-based learning in aging: Contributions and trajectories of change in striatal and hippocampal systems. Journal of Neuroscience, 38(39), 8453-8462.

Lindenberger, U. \& Baltes, P. B. (1994). Sensory functioning and intelligence in old age: A strong connection. Psychology and Aging, 9, 339-55.

Little, D. M., Prentice, K. J., \& Wingfield, A. (2004). Adult age differences in judgments of semantic fit. Appl. Psycholinguist. 25, 135-143.

Lustig, C. \& Flegal, K. (2008). Age differences in memory: Demands on cognitive control and association processes. Advances in Psychology, 139, 137-149.

Lyle, K. B., Bloise, S. M. \& Johnson, M. K. (2006). Age-related binding deficits and the content of false memories. Psychology and Aging, 21, 86-95.

MacKay, A., Connor, L. T., Albert, M. L., \& Obler, L. K. (2002). Noun and verb retrieval in healthy aging. Journal of the International Neuropsychological Society, 8(1), 764-770.

Marien, P., Mampaey, E., Vervaet, A., Saerens, J., \& de Deyn, P. P. (1998). Normative data for the Boston Naming Test in native Dutch-speaking Belgian elderly. Brain and Language, 65(3), 447-467.

Madden, D. J., Pierce, T. W., \& Allen, P. A. (1993). Age-related slowing and the time course of semantic priming in visual word identification. Psychology and Aging, 8, 490-507.

Maillet, D. \& Rajah, M. N. (2013). Association between prefrontal activity and volume change in prefrontal and medial temporal lobes in aging and dementia: A review. Ageing Research Reviews, 12, 479-489.

Maillet, D. \& Rajah, M. N. (2014). Age-related differences in brain activity in the subsequent memory paradigm: A meta-analysis. Neuroscience and Biobehavioral Reviews, 45, 246257.

Mata, R., Josef, A. K., Samanez-Larkin, G. R., \& Hertwig, R. (2011). Age differences in risky choice: A meta-analysis. Annals of the New York Academy of Sciences, 1235(1), 18-29. 
Meinzer, M., Flaisch, T., Wilser, L., Euitz, C., Rockstroh, B., Conway, T., Gonzalez Rothi, L. J., \& Crosson, B. (2009). Neural signatures of semantic and phonemic fluency in young and old adults. Journal of Cognitive Neuroscience, 21, 2007-2018.

Mell, T., Heekeren, H. R., Marschner, A., Wartenburger, I., Villringer, A., \& Reischies, F. M. (2005). Effect of aging on stimulus-reward association learning. Neuropsychologia, 43(4), 554-563.

Miller, E. K. \& Cohen J. D. (2001). An integrative theory of prefrontal cortex function. Annual Review of Neuroscience, 24, 167-202.

Mitchell, K. J., Johnson, M. K., Raye, C. L., \& D'Esposito, M. (2000). FMRI evidence of agerelated hippocampal dysfunction in feature binding in working memory. Brain Research: Cognitive Brain Research, 10, 197-206.

Morcom, A. M., Li, J., Rugg, M. D. (2007). Age effects on the neural correlates of episodic retrieval: Increased cortical recruitment with matched performance. Cerebral Cortex, 17(11), 2491-2506.

Morris, J. S., DeGelder, B., Weiskrantz, L., \& Dolan, R. J. (2001). Differential extrageniculostriate and amygdala responses to presentation of emotional faces in a cortically blind field. Brain, 124(6), 1241-1252.

Mortensen, L., Meyer, A. S., \& Humphreys, G. W. (2006). Age-related effects on speech production: A review. Language and Cognitive Processes, 21, 238-290.

Moscarello, J. M., \& LeDoux, J. E. (2013). Active avoidance learning requires prefrontal suppression of amygdala-mediated defensive reactions. Journal of Neuroscience, 33(9), 3815-3823.

Moscovitch, M. (1992). Memory and working-with-memory: A component process model based on modules and central systems. Journal of Cognitive Neuroscience, 4: 257-267.

Moscovitch, M. \& Winocur, G. (1995). Frontal lobes, memory, and aging. In J. Grafman, K. J. Holyoak, \& F. Boller (Eds.), Structure and functions of the human prefrontal cortex (pp. 119-150). New York, NY: New York Academy of Sciences.

Moss, H. E., Abdallah, S., Fletcher, P., Bright, P., Pilgrim, L., Acres, K., \& Tyler, L. K. (2005). Selecting among competing alternatives: Selection and retrieval in the left inferior frontal gyrus. Cereb. Cortex , 15, 1723-1735.

Naveh-Benjamin, M. (2000). Adult age differences in memory performance: Tests of an 
associative deficit hypothesis. Journal of Experimental Psychology: Learning, Memory and Cognition, 26, 1170-1187.

Naveh-Benjamin, M., Shing, Y. L., Kilb, A., Werkle-Bergner, M., Lindenberger, U., \& Li, S. C. (2009). Adult age differences in memory for name-face associations: The effects of intentional and incidental learning. Memory, 17, 220-232.

Neumann, Y., Obler, L. K., Gomes, H., \& Shafer, V. (2009). Phonological vs sensory contributions to age effects in naming: An electrophysiological study. Aphasiology, 23(78), 1028-1039.

Nilsson, L. G. (2003). Memory function in normal aging. Acta Neurologica Scandinavica, 107, 7-13.

Niv, Y. (2009). Reinforcement learning in the brain. Journal of Mathematical Psychology, 53(3), 139-154.

Norman, D. A. \& Shallice, T. (1986). Attention to action: Willed and automatic control of behavior. In R. J. Davidson, G. E. Schwartz, \& D. Shapiro (Eds.), Consciousness and selfregulation: Advances in research and theory (pp. 1-18). New York, NY: Plenum.

Nyberg L., McIntosh A. R., Houle S., Nilsson L. G., \& Tulving E. (1996). Activation of medial temporal structures during episodic memory retrieval. Nature. 380(6576), 715-717.

Packard, M. G., Hirsh, R., \& White, N. M. (1989). Differential effects of fornix and caudate nucleus lesions on two radial maze tasks: Evidence for multiple memory systems. Journal of Neuroscience, 9(5), 1465-1472.

Park, D. C. \& Reuter-Lorenz, P. (2009). The adaptive brain: Aging and neurocognitive scaffolding. Annual Review of Psychology, 60, 173-196.

Park, D. C., Polk, T. A., Park, R., Minear, M., Savage, A., \& Smith, M. R. (2004). Aging reduces neural specialization in ventral visual cortex. Proc. Natl. Acad. Sci., 101, 13091-13095.

Peelle, J. E., Troiani, V., Wingfield, A., \& Grossman, M. (2010). Neural processing during older adults' comprehension of spoken sentences: Age differences in resource allocation and connectivity. Cereb. Cortex, 20, 773-782.

Persson, J., Kalpouzos, G., Nilsson, L., Ryberg, M., \& Nyberg, L. (2010). Preserved hippocampus activation in normal aging as revealed by fMRI. Hippocampus, 21(7), 753766. doi:10.1002/hipo.20794

Persson, J., Nyberg, L., Lind, J., Larsson, A., Nilsson, L. G., Ingvar, M., \& Buckner, R. L. 
(2006). Structure-function correlates of cognitive decline in aging. Cerebral Cortex, 16, 907-915.

Pfefferbaum, A., Sullivan, E. V., Rosenbloom, M. J., Mathalon, D. H., \& Lim, K. O. (1998). A controlled study of cortical gray matter and ventricular changes in alcoholic men over a 5-year interval. Archives of General Psychiatry, 55, 905-12.

Pietschmann, M., Endrass, T., Czerwon, B., \& Kathmann, N. (2011). Aging, probabilistic learning and performance monitoring. Biological Psychology, 86(1), 74-82.

Poldrack, R. A., Clark, J., Pare-Blagoev, E. J., \& Shohamy, D. (2001). Interactive memory systems in the human brain. Nature, 414(6863), 546-550.

Poldrack, R. A., Wagner, A. D., Prull, M. W., Desmond, J. E., Glover, G. H., Gabrieli, J. D. E. (1999). Functional specialization for semantic and phonological processing in the left inferior prefrontal cortex. Neuroimage, 10, 15-35.

Raz, N., Ghisletta, P., Rodrigue, K. M., Kennedy, K. M., \& Lindenberger, U. (2010). Trajectories of brain aging in middle-aged and older adults: Regional and individual differences. Neuroimage, 51(2), 501-511.

Raz, N., Gunning-Dixon, F. M., Head, D., Dupuis, J. H., McQuain, J., Briggs, S. D., Loken, W. J., Thornton, E. A., \& Acker, J. D. (1997). Selective aging of the human cerebral cortex observed in vivo: Differential vulnerability of the prefrontal gray matter. Cerebral Cortex, 7, 268-282.

Raz, N., Lindenberger, U., Rodrigue, K. M., Kennedy, K. M., Head, D., Williamson, A., ... \& Acker, J. D. (2005). Regional brain changes in aging healthy adults: General trends, individual differences and modifiers. Cerebral Cortex, 15(11), 1676-1689.

Ren, J., Wu, Y. D., Chan, J. S., \& Yan, J. H. (2013). Cognitive aging affects motor performance and learning. Geriatrics \& Gerontology International, 13(1), 19-27.

Resnick, S. M., Pham, D. L., Kraut, M. A., Zonderman, A. B., \& Davatzikos, C. (2003). Longitudinal magnetic resonance imaging studies of older adults: A shrinking brain. Journal of Neuroscience, 23, 3295-301.

Rieckmann, A., Fischer, H., \& Bäckman, L. (2010). Activation in striatum and medial temporal lobe during sequence learning in younger and older adults: Relations to performance. Neuroimage, 50(3), 1303-1312. 
Rodrigue, K. M., Kennedy, K. M., \& Raz, N. (2005). Aging and longitudinal change in perceptual-motor skill acquisition in healthy adults. The Journals of Gerontology: Series B, 60(4), 174-181.

Rodrigue, K. M. \& Raz, N. (2004). Shrinkage of the entorhinal cortex over five years predicts memory performance in healthy adults. Journal of Neuroscience, 24, 956-63.

Roediger, H. L. \& McDermott, K. B. (1993). Implicit memory in normal human subjects. In H. Spinnler \& F. Boller (Eds.), Handbook of Neuropsychology (pp. 63-131). Amsterdam, Netherlands: Elsevier.

Rönnlund, M., Nyberg, L., Bäckman, L., \& Nilsson, L. G. (2005). Stability, growth, and decline in adult life span development of declarative memory: Cross-sectional and longitudinal data from a population-based study. Psychology of Aging, 20, 3-18.

Ryan, J. D., Leung, G., Turk-Browne, N. B., \& Hasher L. (2007). Assessment of age-related changes in inhibition and binding using eye movement monitoring. Psychology and Aging, 22, 239-50.

Salthouse, T. A. (1996). The processing-speed theory of adult age differences in cognition. Psychological Review, 103, 403-428.

Samanez-Larkin, G. R., Gibbs, S. E., Khanna, K., Nielsen, L., Carstensen, L. L., \& Knutson, B. (2007). Anticipation of monetary gain but not loss in healthy older adults. Nature Neuroscience, 10(6), 787-791.

Samanez-Larkin, G. R., \& Knutson, B. (2015). Decision making in the ageing brain: Changes in affective and motivational circuits. Nature Reviews Neuroscience, 16(5), 278-289.

Samanez-Larkin, G. R., Levens, S. M., Perry, L. M., Dougherty, R. F., \& Knutson, B. (2012). Frontostriatal white matter integrity mediates adult age differences in probabilistic reward learning. Journal of Neuroscience, 32(15), 5333-5337.

Samanez-Larkin, G. R., Worthy, D. A., Mata, R., McClure, S. M., \& Knutson, B. (2014). Adult age differences in frontostriatal representation of prediction error but not reward outcome. Cognitive, Affective, \& Behavioral Neuroscience, 14(2), 672-682.

Schacter, D. L., Wig, G. S., \& Stevens, W. D. (2007). Reductions in cortical activity during priming. Current Opinion in Neurobiology, 17(2), 171-176. 
Schott, B. H., Niehaus, L., Wittmann, B. C., Schütze, H., Seidenbecher, C. I., Heinze, H. J., \& Düzel, E. (2007). Ageing and early-stage Parkinson's disease affect separable neural mechanisms of mesolimbic reward processing. Brain, 130(9), 2412-2424.

Schultz, W. (2000). Multiple reward signals in the brain. Nature Reviews Neuroscience, 1(3), 199-207. doi:10.1038/35044563

Schultz, W. (2013). Updating dopamine reward signals. Current Opinion in Neurobiology, 23(2), 229-238.

Schultz, W. (2017). Reward prediction error. Current Biology, 27(10), 369-371.

Schultz, W., Dayan, P., \& Montague, P. R. (1997). A neural substrate of prediction and reward. Science, 275, 1593-1599.

Schnur, T. T., Schwartz, M. F., Kimberg, D. Y., Hirshorn, E., Coslett, H. B., \& ThompsonSchill, S.L. (2009). Localizing interference during naming: Convergent neuroimaging and neuropsychological evidence for the function of Broca's area. Proc. Natl. Acad. Sci., $106,322-327$.

Schwartz, S., Maquet, P., \& Frith, C. (2002). Neural correlates of perceptual learning: A functional MRI study of visual texture discrimination. Proceedings of the National Academy of Sciences, 99(26), 17137-17142.

Sebastián, M. \& Ballesteros, S. (2012). Effects of normal aging on event-related potentials and oscillatory brain activity during a haptic repetition priming task. Neuroimage, 60(1), 720.

Severson, J. A., Marcusson, J., Winblad, B., \& Finch, C. E. (1982). Age-correlated loss of dopaminergic binding sites in human basal ganglia. Journal of Neurochemistry, 39(6), 1623-1631.

Shohamy, D., \& Wagner, A. D. (2008). Integrating memories in the human brain: hippocampalmidbrain encoding of overlapping events. Neuron, 60(2), 378-389.

Smith, K. S., \& Graybiel, A. M. (2013). A dual operator view of habitual behavior reflecting cortical and striatal dynamics. Neuron, 79(2), 361-374.

Smith, A. D., Park, D. C., Earles, J. L. K., Shaw, R. J., \& Whiting, W. L. (1998). Age differences in context integration in memory. Psychology and Aging, 13, 21-28. 
Solomon, P. R., Pomerleau, D., Bennett, L., James, J., \& Morse, D. L. (1989). Acquisition of the classically conditioned eyeblink response in humans over the life span. Psychology and aging, 4(1), 34-41.

Spencer, R. M., Gouw, A. M., \& Ivry, R. B. (2007). Age-related decline of sleep-dependent consolidation. Learning \& Memory, 14(7), 480-484.

Spencer, W. D \& Raz, N. (1995). Differential effects of aging on memory for content and context: A meta-analysis. Psychology and Aging, 10, 527-539.

Squire, L. R. (2004). Memory systems of the brain: A brief history and current perspective. Neurobiology of learning and memory, 82(3), 171-177.

Squire, L. R. (2009). Memory and brain systems: 1969-2009. Journal of Neuroscience, 29(41), 12711-12716.

Squire, L. R., \& Dede, A. J. O. (2015). Conscious and unconscious memory systems. Cold Spring Harbor Perspectives in Biology, 7(3), 1-14. http://doi.org/10.1101/cshperspect.a021667

Squire, L. \& Zola-Morgan, S. (1991). The medial temporal lobe memory system. Science, 253, 1380-1386.

Sutton, R. S., \& Barto, A. G. (1998). Reinforcement learning: An introduction. Cambridge, MA: The MIT Press.

Thompson, R. F., \& Steinmetz, J. E. (2009). The role of the cerebellum in classical conditioning of discrete behavioral responses. Neuroscience, 162(3), 732-755.

Thompson-Schill, S. L., Bedny, M., \& Goldberg, R. F. (2005). The frontal lobes and the regulation of mental activity. Current Opinion in Neurobiology, 15, 219-224.

Thompson-Schill, S. L., D'Esposito, M., Aguirre, G. K., \& Farah, M. J. (1997). Role of left inferior prefrontal cortex in retrieval of semantic knowledge: A reevaluation. Proceedings of the National Academy of Sciences, 94, 14792-14797.

Thorndike, E. L. (1911). Animal Intelligence: Experimental studies. New York, NY: The Macmillan Company.

Thürling, M., Galuba, J., Thieme, A., Burciu, R. G., Göricke, S., Beck, A., ... \& Timmann, D. (2014). Age effects in storage and extinction of a naturally acquired conditioned eyeblink response. Neurobiology of Learning and Memory, 109, 104-112. 
Thürling, M., Kahl, F., Maderwald, S., Stefanescu, R. M., Schlamann, M., Boele, H. J., ... \& Timmann, D. (2015). Cerebellar cortex and cerebellar nuclei are concomitantly activated during eyeblink conditioning: A 7T fMRI study in humans. Journal of Neuroscience, 35(3), 1228-1239.

Tsukiura, T. \& Cabeza, R. (2008). Orbitofrontal and hippocampal contributions to memory for face-name associations: The rewarding power of a smile. Neuropsychologia, 46, 2310-9.

Tulving, E. (1983). Elements of episodic memory. Oxford, England: Oxford University Press.

Tyler, L. K., Marslen-Wilson, W. D., Randall, B., Wright, P., Devereux, B. J., Zhuang, J., Papoutsi, M., \& Stamatakis, E. A. (2011). Left inferior frontal cortex and syntax:

Function, structure and behaviour in patients with left hemisphere damage. Brain, 134, 415-31.

Tyler, L. K., Shafto, M. A., Randall, B., Wright, P., Marslen-Wilson, W. D., \& Stamatakis, E. A. (2010). Preserving syntactic processing across the adult life span: The modulation of the frontotemporal language system in the context of age-related atrophy. Cerebral Cortex, 20,352-364.

Van de Vijver, I., Ridderinkhof, K. R., \& de Wit, S. (2015). Age-related changes in deterministic learning from positive versus negative performance feedback. Aging, Neuropsychology, and Cognition, 22(5), 595-619.

Van Halteren-Van Tilborg, I. A., Scherder, E. J., \& Hulstijn, W. (2007). Motor-skill learning in Alzheimer's disease: A review with an eye to the clinical practice. Neuropsychology Review, 17(3), 203-212.

Verhaeghen, P. (2003). Aging and vocabulary score: A meta-analysis. Psychology and Aging, $18,332-339$.

Verhaegen, C. \& Poncelet, M. (2013). Changes in naming and semantic abilities with aging from 50-90 years. Journal of the International Neuropsychological Society, 19, 119-126.

Voelcker-Rehage, C. (2008). Motor-skill learning in older adults: A review of studies on agerelated differences. European Review of Aging and Physical Activity, 5(1), 5-16.

Wagner, A. D., Schacter, D. L., Rotte, M., Koutstaal, W., Maril, A., Dale, A. M., Rosen, B. R., \& Buckner, R. L. (1998). Building memories: Remembering and forgetting of verbal experiences as predicted by brain activity. Science, 281, 1188-1191. 
Wais, P. E., Squire, L. R., \& Wixted, J. T. (2010). In search of recollection and familiarity signals in the hippocampus. Journal of Cognitive Neuroscience, 22(1), 109-123. doi:10.1162/jocn.2009.21190

Wais, P. E., Wixted, J. T. Hopkins, R., \& Squire, L. R. (2006). The hippocampus supports both the recollection and the familiarity components of recognition memory. Neuron, 49, 459466.

Walhovd, K. B., Westlye, L. T., Amlien, I., Espeseth, T., Reinvang, I., Raz, N., ... \& Dale, A. M. (2011). Consistent neuroanatomical age-related volume differences across multiple samples. Neurobiology of Aging, 32(5), 916-932.

Ward, E. V., Berry, C. J., \& Shanks, D. R. (2013). Age effects on explicit and implicit memory. Frontiers in Psychology, 4(639), 1-11.

Weiler, J. A., Bellebaum, C., \& Daum, I. (2008). Aging affects acquisition and reversal of reward-based associative learning. Learning \& Memory, 15(4), 190-197.

Wierenga, C. E., Benjamin, M., Gopinath, K., Perlstein, W. M., Leonard, C. M., Rothi, L. J., Conway, T., Cato, M. A., Briggs, R., \& Crosson, B. (2008). Age-related changes in word retrieval: Role of bilateral frontal and subcortical networks. Neurobiology of Aging, $29,436-451$.

West, R. L. (1996). An application of prefrontal cortex function theory to cognitive aging. Psychological Bulletin, 120, 272-292.

Wiggs, C. L., \& Martin, A. (1998). Properties and mechanisms of perceptual priming. Current Opinion in Neurobiology, 8, 227-233.

Willingham, D. B., \& Goedert-Eschmann, K. (1999). The relation between implicit and explicit learning: Evidence for parallel development. Psychological Science, 10(6), 531-534.

Willingham, D. B., Salidis, J., \& Gabrieli, J. D. (2002). Direct comparison of neural systems mediating conscious and unconscious skill learning. Journal of Neurophysiology, 88(3), 1451-1460.

Wilson, J. K., Baran, B., Pace-Schott, E. F., Ivry, R. B., \& Spencer, R. M. (2012). Sleep modulates word-pair learning but not motor sequence learning in healthy older adults. Neurobiology of Aging, 33(5), 991-1000. 
Wimmer, G. E., Braun, E. K., Daw, N. D., \& Shohamy, D. (2014). Episodic memory encoding interferes with reward learning and decreases striatal prediction errors. Journal of Neuroscience, 34(45), 14901-14912.

Wong, D. F., Wagner Jr., H. N., Dannals, R. F., Links, J. M., Frost, J. J., Ravert, H. T., ... \& Petronis, J. D. (1984). Effects of age on dopamine and serotonin receptors measured by positron tomography in the living human brain. Science, 226, 1393-1397.

Wood, S., Busemeyer, J., Koling, A., Cox, C. R., \& Davis, H. (2005). Older adults as adaptive decision makers: Evidence from the Iowa Gambling Task. Psychology and Aging, 20(2), 220-225.

Woodruff-Pak, D. S., Goldenberg, G., Downey-Lamb, M. M., Boyko, O. B., \& Lemieux, S. K. (2000). Cerebellar volume in humans related to magnitude of classical conditioning. Neuroreport, 11(3), 609-615.

Yonelinas, A. P. (2002). The nature of recollection and familiarity: A review of 30 years of research. Journal of Memory and Language, 46, 441-517.

Yonelinas, A. P., Widaman, K., Mungas, D., Reed, B., Weiner, M. W., \& Chui, H. C. (2007). Memory in the aging brain: Doubly dissociating the contribution of the hippocampus and entorhinal cortex. Hippocampus, 17, 1134-40.

Yin, H. H., Mulcare, S. P., Hilário, M. R., Clouse, E., Holloway, T., Davis, M. I., ... \& Costa, R. M. (2009). Dynamic reorganization of striatal circuits during the acquisition and consolidation of a skill. Nature Neuroscience, 12(3), 333-341.

Zhuang, J., Johnson M. A., Madden, D. J., Burke, D. M., \& Diaz, M. T. (2016). Age-related differences in resolving semantic and phonological competition during receptive language tasks. Neuropsychologia, 93, 189-199. 